Article

\title{
Optimization of Thermoplastic Blend Matrix HDPE/PLA with Different Types and Levels of Coupling Agents
}

\author{
Alessia Quitadamo ${ }^{1,2}$, Valérie Massardier ${ }^{2}$, Carlo Santulli ${ }^{3}$ and Marco Valente ${ }^{1, *(1)}$ \\ 1 Department of Chemical and Material Engineering, Università di Roma La Sapienza, via Eudossiana 18, \\ 00184 Rome, Italy; alessia.quitadamo@uniroma1.it \\ 2 Ingénierie des Matériaux Polymères, INSA de Lyon, Université de Lyon 69003, 69621 Villeurbanne, France; \\ valerie.massardier@insa-lyon.fr \\ 3 School of Architecture and Design, Università di Camerino, Viale della Rimembranza, 63100 Ascoli Piceno, \\ Italy; carlo.santulli@unicam.it \\ * Correspondence: marco.valente@uniroma1.it; Tel.: +39-06-4458-5582
}

Received: 13 November 2018; Accepted: 6 December 2018; Published: 12 December 2018

check for updates

\begin{abstract}
High-density polyethylene (HDPE) and poly(lactic) acid (PLA) blends with different ratios of both polymers, namely, 30:70, 50:50, and 70:30, were produced. Polyethylene-grafted maleic anhydride and a random copolymer of ethylene and glycidyl methacrylate were also considered as compatibilizers to modify HDPE/PLA optimal blends and were added in the amounts of 1,3 , and 5 wt.\%. Different properties of the blends were evaluated by performing tensile tests and scanning electron microscopy to analyze blend and interfaces morphology. Moreover, thermomechanical analysis through differential scanning calorimetry, thermo-gravimetric analysis, and infrared spectroscopy were also performed. The blend containing equal amounts of HDPE and PLA seemed to present a good balance between amount of bio-derived charge and acceptable mechanical properties. This suggests that these blends have a good potential for the production of composites with lingo-cellulosic fillers.
\end{abstract}

Keywords: blend; bio-derived polymers; compatibilization; thermoplastic matrix for composite

\section{Introduction}

Blending is one of the simplest and widespread methods to improve polymer properties. In fact, low-cost processing, typical of common blend manufacturing, allows obtaining the desired properties and a high variety of products [1]. As a consequence, nowadays polymer blends represent around half of the total plastic production [2]. The main limit of a polymer blend is the mutual miscibility of polymers. In fact, as established by the second law of thermodynamics, the variation of free energy $\Delta \mathrm{G}$ is usually positive because of the high polymerization degree of polymers (affecting the variation of entropy $\Delta S$ ) and the poor affinity between polymers (affecting the variation of enthalpy $\Delta H$ ) [3].

One of the main parameters affecting polymers miscibility is interfacial tension. In particular, higher interfacial tension leads to higher phase separation [4]. In spite of this limit, a polymer blend can be compatibilized in order to increase dispersion and adhesion between polymers [5]. Many strategies have been developed in this context, among which, the introduction of a compatibilizer is one of the most adopted [6]. Recently, higher sensitivity to problems of oil-based polymer pollution has developed, stimulating research on bio-derived polymer production for application as potential substitutes of oil-based polymers [7-10]. Among bio-derived polymers, poly(lactic) acid (PLA) seems to be one of the most studied and applied, thanks to its properties which are comparable 
to or in some cases higher than traditional polyolefins [11-14]. PLA, in fact, has been frequently selected as a bio-derived polymer to obtain blends with a high amount of biodegradable polymer, reducing the amount of polyolefin [15-17]. Moreover, depending on the compatibilizer added, an oil-based, bio-derived blend can be optimized and has specific properties. For example, a recent study compatibilized PLA/ high-density polyethylene (HDPE) polymer blends with cobalt stearate in view of a possible oxo-degradation process. This demonstrates the wide range of opportunities deriving from the addition of the right type and amount of compatibilizer [18]. Several compatibilizing methods have been studied in order to improve oil-based-bio-derived polymeric blends, such as the use of functional molecules for reactive compatibilization during extrusion or the addition of a commercial modified polymer as a coupling agent [19-21]. Usually, chemical compatibilization, obtained with the use of grafted polymers or random copolymers, is performed to reduce the size of the dispersed phase thanks to functional groups' reactivity. In this way, a reduction of interfacial tension and of the coalescence impediment of the dispersed phase is possible [22].

The development of an oil-based, bio-derived thermoplastic blend was therefore the preliminary goal of this work. In particular, an optimized high-density polyethylene and poly(lactic) acid blend could be produced in order to obtain oil-based-bio-derived thermoplastic blends with high amounts of bio-derived charge, while maintaining good mechanical properties.

Two kinds of compatibilizers were tested in order to improve the blend properties. Polybond 3029 and Lotader AX8840 seemed to be effective, thanks to the presence of maleic anhydride grafted on polyethylene chains for the former and polyethylene random copolymer with glycidyl methacrylate for the latter.

\section{Materials and Methods}

Eraclene MP90, commercial name of high-density polyethylene (HDPE) from ENI (Versalis, San Donato Milanese, Italy), was selected as the oil-based polymer. Among its properties are: a melt flow index (MFI) of $7 \mathrm{~g} / 10 \mathrm{~min}\left(190{ }^{\circ} \mathrm{C} / 2.16 \mathrm{~kg}\right)$, a nominal mass of $0.96 \mathrm{~g} / \mathrm{cm}^{3}$, a tensile strength of $21 \mathrm{MPa}$, a tensile modulus of $1.2 \mathrm{GPa}$, and a Shore D hardness of 50. Poly(lactic acid) (PLA) Ingeo Biopolymer 3251D from Nature Works (Minnetonka, MN, USA) was selected as a bio-derived thermoplastic polymer, with an MFI of $35 \mathrm{~g} / 10 \mathrm{~min}\left(190^{\circ} \mathrm{C} / 2.16 \mathrm{~kg}\right)$. This polymer is characterized by density 1.24 , crystalline melting temperature in the range $155-170{ }^{\circ} \mathrm{C}$, and a glass transition temperature in the range $55-60^{\circ} \mathrm{C}$. Polybond 3029 (Addivant, CT, USA) was selected as an additive, suitable for cellulosic fillers. In fact, Polybond 3029 is a maleated polyethylene with a melt flow index of $4 \mathrm{~g} / 10 \mathrm{~min}\left(190^{\circ} \mathrm{C} / 2.16 \mathrm{~kg}\right)$, and a maleic anhydride (MA) content of $1.7 \mathrm{wt} . \%$ (high). Generally, it is sold as pellets of 3-4 mm diameter. Lotader AX8840 was selected with the same purpose. It is a random copolymer of ethylene and glycidyl-methacrylate (GMA), with a melt flow index of $5 \mathrm{~g} / 10$ $\min \left(190{ }^{\circ} \mathrm{C} / 2.16 \mathrm{~kg}\right)$. The GMA content is about $8 \mathrm{wt}$. $\%$. PLA was dried for one night at $80{ }^{\circ} \mathrm{C}$ in order to avoid possible bubble formation due to water evaporation during the production process.

A Micro 15 Twin-screw DSM research extruder (Xplore Instruments BV, 6160 MD Geleen, The Netherlands) was used in order to produce the samples. Temperature of $180{ }^{\circ} \mathrm{C}$, screw speed of $75 \mathrm{rpm}$, nitrogen atmosphere, and a resident time of $4 \mathrm{~min}$ in the extruder were selected to avoid PLA degradation during the process [11-24].

Injection moulding was used to obtain dog-bone specimens, with a mould temperature of $55^{\circ} \mathrm{C}$ and pressure parameters depending on polymer viscosity. For each family of samples, 10 specimens were produced. Table 1 sums up the formulations produced. 
Table 1. Formulations produced (10 samples for each family). HDPE: high-density polyethylene, PLA: poly(lactic) acid.

\begin{tabular}{ccccc}
\hline Samples & HDPE (\%) & PLA (\%) & Polybond 3029 (\%) & Lotader AX8840 (\%) \\
\hline HDPE70/PLA30 & 70 & 30 & & \\
HDPE50/PLA50 & 50 & 50 & & \\
HDPE30/PLA70 & 30 & 70 & & \\
HDPE50/PLA50-Poly1 & 49.5 & 49.5 & 3 & \\
HDPE50/PLA50-Poly3 & 48.5 & 48.5 & 5 & \\
HDPE50/PLA50-Poly5 & 47.5 & 47.5 & & 3 \\
HDPE50/PLA50-Lot1 & 49.5 & 49.5 & & 5 \\
HDPE50/PLA50-Lot3 & 48.5 & 48.5 & & \\
HDPE50/PLA50-Lot5 & 47.5 & 47.5 & & \\
\hline
\end{tabular}

\subsection{Tensile Tests}

Tensile tests were performed in accordance with the ASTM D638-14 standard, using Zwick/Roell Z010 (ZwickRoell GmbH \& Co. KG, D-89079 Ulm, Germany), with a load cell of $10 \mathrm{kN}$ and a $50 \mathrm{~N}$ preload. The crosshead speed was $5 \mathrm{~mm} / \mathrm{min}$. The tensile tests were performed on five dog-bone samples per series, with a gauge length section of $30 \times 4 \times 2 \mathrm{~mm}^{3}(\mathrm{~L} \times \mathrm{W} \times \mathrm{T})$. For each family, five samples were tested.

\subsection{Scanning Electron Microscopy (SEM)}

The samples were observed with a Hitachi S2500 25 kV scanning electron microscope (Hitachi, Krefeld, Germany) in order to analyze blend morphology and interfaces. The samples were sputter-coated with gold particles before surface characterization.

\subsection{Quartering}

The samples produced, in the majority of cases, were characterized by some heterogeneity because of multiphase matrices. In order to obtain reliable results from the thermal analysis and analyze a representative number of samples, a cryogenic mill was adopted to obtain samples in the form of powders. A subsequent statistical approach, quartering, was used to select an exemplary number of samples used for chemical and thermal analysis. This method was based on the separation of the total amount of charge in four parts equal in weight. Then, two parts at the opposite side were mixed together, and the other two were separated.

\subsection{Differential Scanning Calorimetry (DSC)}

Differential Scanning Calorimetry (DSC) tests were performed on a Q20 Thermal Analysis instrument (TA Instruments, New Castle, DE, USA) from $25^{\circ} \mathrm{C}$ to $180^{\circ} \mathrm{C}$ at $10^{\circ} \mathrm{C} / \mathrm{min}$ under a nitrogen flow of $50 \mathrm{~mL} / \mathrm{min}^{-1}$. Two cycles were performed with a $4 \mathrm{~min}$ interval between them at $180^{\circ} \mathrm{C}$ to eliminate trace of thermal history. The first cycle provided information about properties after injection moulding, while the second one gave material's properties. Cold crystallization, melting, crystallization parameters (temperature and enthalpy), and glass transition temperatures were analyzed.

\subsection{Thermogravimetric Analysis (TGA)}

Thermogravimetric Analysis (TGA) tests were carried out on a Q500 Thermal Analysis instrument (TA Instruments, New Castle, DE, USA) up to $600{ }^{\circ} \mathrm{C}$, with a scanning temperature of $10^{\circ} \mathrm{C} / \mathrm{min}$ under a nitrogen flow of $50 \mathrm{~mL} / \mathrm{min}^{-1}$. From this analysis, we derived temperatures at which degradation started $\left(\mathrm{T}_{\text {onset }}\right)$, evaluated through the extrapolated onset temperature from the TGA curve and the $\Delta \mathrm{m}$, i.e., mass variation, during the test. 


\subsection{Attenuated Total Reflection-Fourier Transform Infrared (ATR-FTIR) Analysis}

Attenuated Total Reflection-Fourier Transform Infrared (ATR-FTIR) tests were carried out to evaluate the interactions between HDPE, PLA, and the compatibilizers. The tests were performed with a thermo-scientific Nicolet IS10 spectrometer (Thermo Fisher Scientific, Waltham, MA, USA) with a spectral range $4000-400 \mathrm{~cm}^{-1}$ and 32 scans.

\section{Results}

\subsection{Tensile Tests}

HDPE/PLA blends' properties were first analyzed through tensile tests of HDPE70/HDPE30, HDPE50/PLA50, and HDPE30/PLA70 to evaluate mechanical performance and identify the influence of polymer blend. Table 2 sums up the results of these three blends compared to neat HDPE and PLA, while Figure 1 displays the tensile tests curves of the HDPE/PLA blends.

Table 2. Tensile tests results of HDPE/PLA blends without compatibilizers.

\begin{tabular}{cccc}
\hline Samples & $\mathbf{E}(\mathbf{G P a})$ & $\boldsymbol{\sigma} \mathbf{( M P a})$ & $\boldsymbol{\varepsilon}(\mathbf{\%})$ \\
\hline HDPE & $1.16 \pm 0.08$ & $21.59 \pm 0.18$ & $>400$ \\
PLA & $3.04 \pm 0.02$ & $57.34 \pm 1.00$ & $7.1 \pm 0.3$ \\
HDPE70/PLA30 & $1.51 \pm 0.05$ & $30.76 \pm 0.73$ & $>400$ \\
HDPE50/PLA50 & $1.88 \pm 0.05$ & $38.73 \pm 0.18$ & $99.4 \pm 2.1$ \\
HDPE30/PLA70 & $2.41 \pm 0.05$ & $49.51 \pm 0.60$ & $2.3 \pm 0.5$ \\
\hline
\end{tabular}

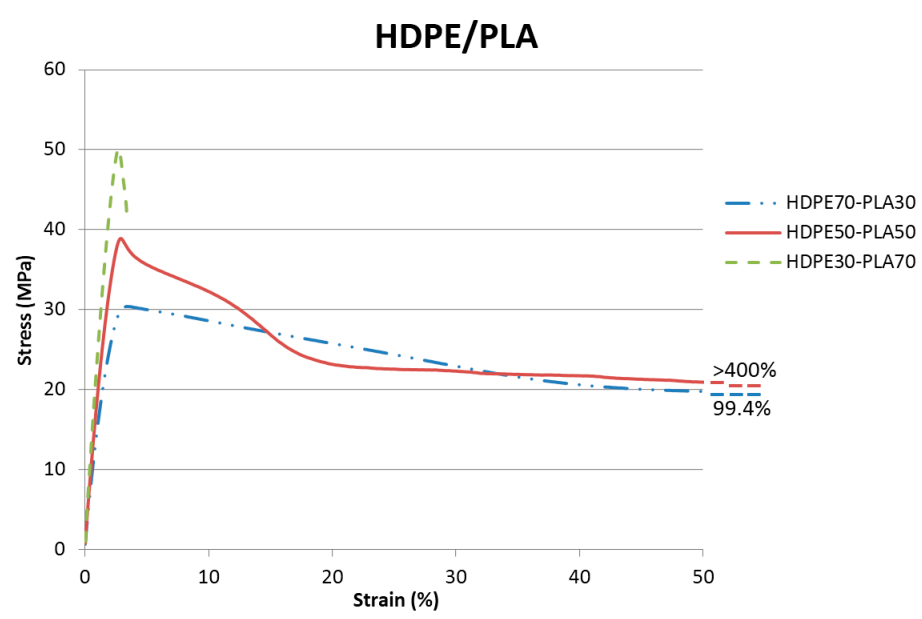

Figure 1. Tensile tests graphs of HDPE70/PLA30, HDPE50/PLA50, and HDPE30/PLA70.

The presence of 30 and 50 wt.\% PLA allowed reaching a good tensile stiffness and strength with respect to neat HDPE, while at the same time keeping acceptable elongation at break. This is a significant result considering the considerable amount of brittle polymer (PLA) blended with HDPE. In contrast, increasing the amount of PLA up to $70 \mathrm{wt} . \%$ strongly reduced the elongation at break, at a level even lower than that for neat PLA, while offering a tensile strength and stiffness near to those of neat PLA [25]. Starting from these results, HDPE50/PLA50 was selected as a promising blend, offering a good compromise of mechanical properties and amount of bio-based material. As a consequence, the analysis of blends with $50 \mathrm{wt} . \%$ PLA were considered for deeper studies. The use of three different percentages of compatibilizers was investigated to elucidate their effects on HDPE50/PLA50 and to identify the most suitable compatibilizer and its amount. In particular, Lotader AX8840 and Polybond 3029 were investigated as compatibilizing agents in the amounts of 1, 3, and 5 wt.\%. Table 3 and Figure 2 display the main tensile tests results. 
Table 3. Tensile tests results for HDPEPLA blends with Lotader AX8840 and Polybond 3029 in different amounts (1, 3, $5 \mathrm{wt}$.\%). The purple colour indicates or Polybond 3029 addition, while the green colour is for Lotader AX8840.

\begin{tabular}{cccc}
\hline Samples & E (GPa) & $\boldsymbol{\sigma} \mathbf{( M P a )}$ & $\varepsilon \mathbf{~ ( \% )}$ \\
\hline HDPE50/PLA50 & $1.88 \pm 0.05$ & $38.73 \pm 0.18$ & $99.4 \pm 2.1$ \\
HDPE50/PLA50-Poly1 & $2.24 \pm 0.76$ & $43.30 \pm 2.76$ & $86.2 \pm 17.3$ \\
HDPE50/PLA50-Poly3 & $2.31 \pm 0.14$ & $42.80 \pm 2.65$ & $71.9 \pm 46.9$ \\
HDPE50/PLA50-Poly5 & $1.92 \pm 0.03$ & $39.74 \pm 0.41$ & $34.1 \pm 13.1$ \\
HDPE50/PLA50-Lot1 & $2.18 \pm 0.21$ & $40.70 \pm 3.99$ & $175.3 \pm 84.2$ \\
HDPE50/PLA50-Lot3 & $2.14 \pm 0.07$ & $41.70 \pm 1.93$ & $193.0 \pm 59.1$ \\
HDPE50/PLA50-Lot5 & $1.75 \pm 0.13$ & $34.28 \pm 1.52$ & $173.2 \pm 56.2$ \\
\hline
\end{tabular}

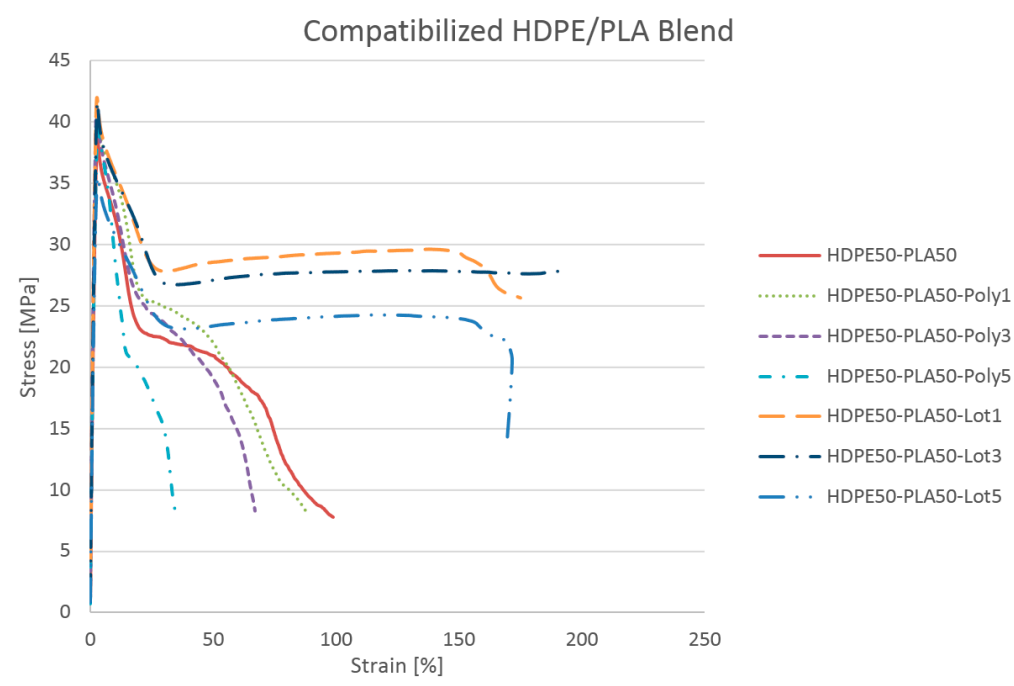

Figure 2. Effect of Lotader AX8840 and Polybond 3029 at 1, 3, and 5 wt.\% on the PE50/PLA50 blend.

Lotader AX8840 and Polybond 3029 were selected because of their ability to interact with both polyethylene and polymers with polar groups, such as poly(lactic) acid. The addition of Lotader AX8840 seemed to be very effective in improving the compatibility between HDPE and PLA, compared to other compatibilizing agents [26,27]. Significant improvement in elongation at break was displayed for all compatibilizer percentages, despite the presence of a high percentage of brittle polymer like PLA. At the same time, slight reductions in elastic modulus and tensile strength were displayed for the highest compatibilizer percentage. Moreover, Polybond 3029 similarly displayed a reduction of $\sigma$ and $\varepsilon$ when 5 wt.\% was added. As a consequence, an optimal amount of Lotader AX8840 and Polybond 3029 need to be applied. In both cases, the best results were obtained for $3 \mathrm{wt} . \%$ of compatibilizer.

\subsection{Scanning Electron Microscopy (SEM)}

Scanning electron microscopy (SEM, Hitachi, Krefeld, Germany) analyses aimed at investigating both the compatibility between HDPE and PLA and the influence of compatibilizers in the blend. HDPE/PLA SEM images displayed the typical immiscible blend morphology obtained when mixing hydrophobic (polyethylene) and hydrophilic (poly (lactic) acid) compounds (Figure 3). In fact, a visible phase separation between HDPE and PLA was displayed, as expected for polymers with different hydrophilicity, a weak interface between HDPE and PLA was evident. The problem of compatibilization between polyethylene and poly(lactic) acid polymers is of paramount importance in recent resin manufacturing and has been partially addressed with interfacially localized catalysts, based for example on stannous octoate [28]. However, the problem appear in general terms far from being totally resolved. 


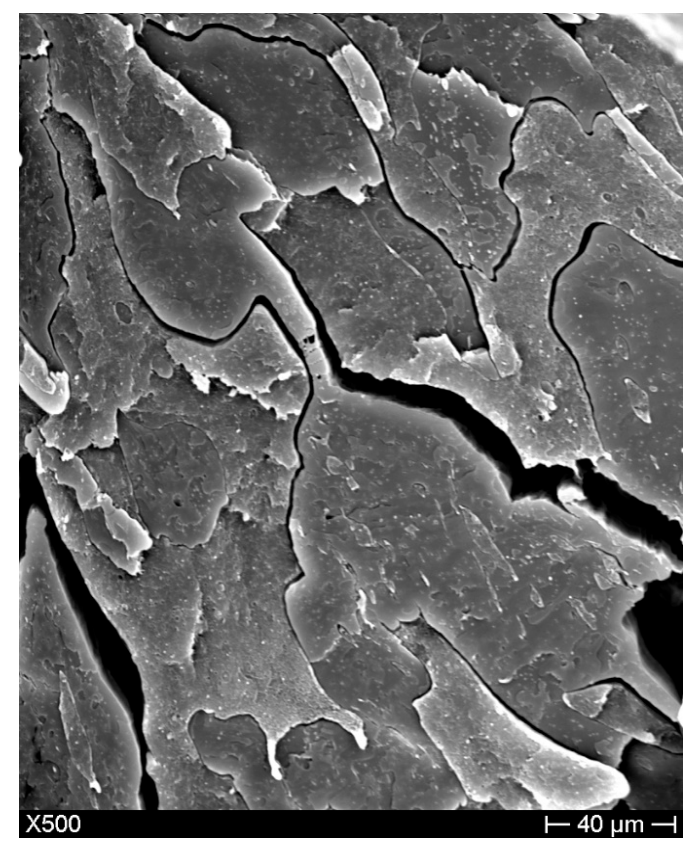

Figure 3. Morphology of the cryo-fractured surface of the HDPE50/PLA50 blend.

The addition of compatibilizers to the HDPE50/PLA50 blend allowed a reduction in dimension of the different phases, suggesting a higher compatibility between HDPE and PLA. This result was more evident for Lotader AX8840 (Figure 4a) than for Polybond 3029 (Figure 4b). In fact, a higher phase separation and easier distinction between polymers were displayed by samples compatibilized with Polybond 3029. The higher affinity of PLA for Lotader AX8840 was already shown in our previous work [11], revealing the presence of a smaller spherical secondary phase for Lotader AX8840 than for Polybond 3029 when blended with PLA. The reactive groups of the compatibilizers can interact with the hydroxyl and/or carboxyl groups of PLA, while the ethylene chain of the compatibilizers can easily be mixed with HDPE. These results are in agreement with the FTIR analyses.

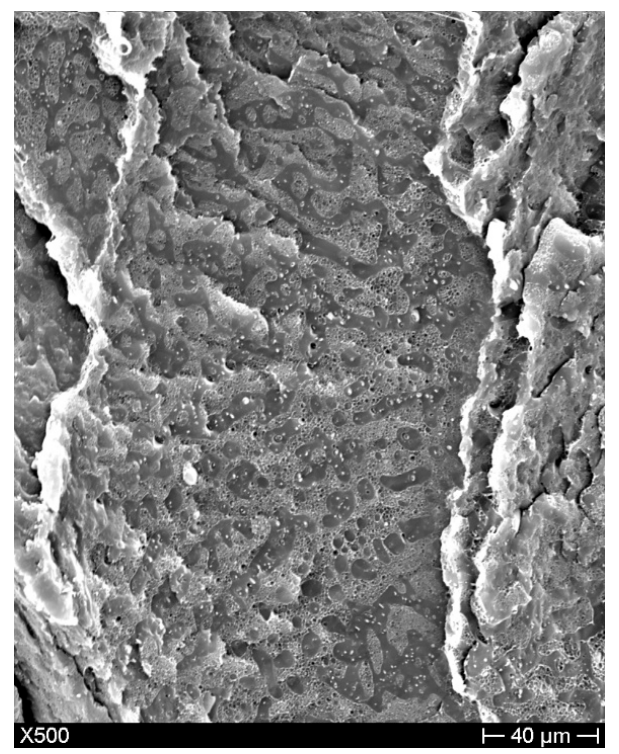

(a)

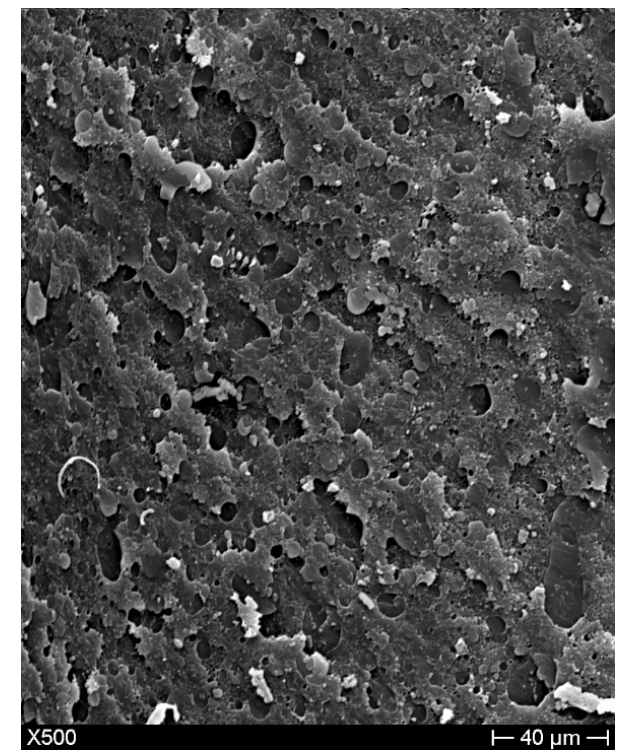

(b)

Figure 4. Blend morphology of the cryo-fractured surface of (a) HDPE50/PLA50-Lot3, (b) HDPE50/PLA50-Poly3. 


\subsection{Differential Scanning Calorimetry (DSC)}

Differential Scanning Calorimetry was useful for analyzing the effects of blending HDPE with PLA and those of adding compatibilizers. $\Delta \mathrm{Hm}_{\mathrm{PE}}(\mathrm{J} / \mathrm{gPE})$ and $\Delta \mathrm{Hm}_{\mathrm{PLA}}(\mathrm{J} / \mathrm{gPLA})$ refer the enthalpy values to the exact amount of polyethylene and poly(lactic) acid in the samples. For example, HDPE50/PLA50 displayed $\Delta \mathrm{Hm}_{\mathrm{PE}}$ of $113 \mathrm{~J} / \mathrm{g}$, but dividing by 0.5 is needed to obtain the real amount of enthalpy for HDPE. As a consequence, the effective $\Delta \mathrm{Hm}_{\mathrm{PE}}$ was $226 \mathrm{~J} / \mathrm{g}_{\mathrm{PE}}$. Table 4 sums up the DSC results for HDPE, PLA, and HDPE50/PLA50.

Table 4. Differential scanning calorimetry (DSC) results for HDPE, PLA, and HDPE50/PLA50.

\begin{tabular}{cccccccc}
\hline & $\Delta$ Hcc $_{\text {PLA }}$ & $\mathbf{T c C}$ & $\Delta$ Hm $_{\text {PE }}$ & $\operatorname{Tm}_{\text {PE }}$ & $\Delta$ Hm $_{\text {PLA }}$ & $\mathbf{T m}_{\text {PLA }}$ & $\operatorname{Tg}_{\text {PLA }}$ \\
\cline { 2 - 8 } & $\mathbf{( J / g _ { \text { PLA } } )}$ & $\left({ }^{\circ} \mathbf{C}\right)$ & $\left(\mathbf{J} / \mathbf{g}_{\text {PE}}\right)$ & $\left({ }^{\circ} \mathbf{C}\right)$ & $\left(\mathbf{J} / \mathbf{g}_{\text {PLA }}\right)$ & $\left({ }^{\circ} \mathbf{C}\right)$ & $\left({ }^{\circ} \mathbf{C}\right)$ \\
\hline HDPE & - & - & 215 & 134 & - & - & - \\
PLA & 7 & 98 & - & - & 41 & 168 & 61 \\
HDPE50/PLA50 & 8 & 97 & 226 & 132 & 40 & 168 & 62 \\
\hline
\end{tabular}

The typical PLA cold crystallization process [29] was still evident in HDPE50/PLA50 blend. Moreover, a slightly higher crystallinity of the HDPE phase was demonstrated, in agreement with both higher mechanical properties of the blend and the occurrence of phase separation because of the presence of crystals [4]. The effects of Lotader AX8840 and Polybond 3029 on HDPE50/PLA50 properties were also analyzed (Table 5). Both Polybond 3029 and Lotader AX8840 addition revealed the presence of cold crystallization. Higher enthalpies values were measured for Lotader AX8840 addition than for Polybond 3029, but in both cases, the influence of adding different amounts of compatibilizers was not evident. A possible interpretation for higher enthalpies is that the addition of compatibilizers results in an increased PLA chain mobility with respect to neat HDPE50/PLA50.

A more evident effect of compatibilizer addition was displayed by Lotader AX8840, with a lower melting enthalpy for the HDPE phase. This result suggests an interaction between HDPE and PLA through Lotader AX8840, hindering HDPE macromolecules mobility [30].

Table 5. DSC results of HDPE50/PLA50 with 1, 3, 5 wt.\% of Lotader AX8840 and Polybond 3029.

\begin{tabular}{|c|c|c|c|c|c|c|c|}
\hline & $\Delta$ Hcc $_{\text {PLA }}$ & Tcc & $\Delta \mathrm{Hm}_{\mathrm{PE}}$ & $\operatorname{Tm}_{\mathrm{PE}}$ & $\Delta \mathrm{Hm}_{\text {PLA }}$ & $\operatorname{Tm}_{\text {PLA }}$ & $\mathrm{Tg}_{\text {PLA }}$ \\
\hline & $\left(\mathrm{J} / \mathrm{g}_{\text {PLA }}\right)$ & $\left({ }^{\circ} \mathrm{C}\right)$ & $\left(\mathrm{J} / \mathrm{g}_{\mathrm{PE}}\right)$ & $\left({ }^{\circ} \mathrm{C}\right)$ & $\left(\mathrm{J} / \mathrm{g}_{\text {PLA }}\right)$ & $\left({ }^{\circ} \mathrm{C}\right)$ & $\left({ }^{\circ} \mathrm{C}\right)$ \\
\hline HDPE50/PLA50 & 8 & 97 & 236 & 132 & 40 & 168 & 62 \\
\hline HDPE50/PLA50-Poly1 & 15 & 94 & 195 & 132 & 45 & 168 & 61 \\
\hline HDPE50/PLA50-Poly3 & 15 & 100 & 190 & 132 & 41 & 168 & 61 \\
\hline HDPE50/PLA50-Poly5 & 16 & 101 & 198 & 132 & 41 & 168 & 61 \\
\hline HDPE50/PLA50-Lot1 & 20 & 103 & 192 & 132 & 40 & 168 & 61 \\
\hline HDPE50/PLA50-Lot3 & 21 & 103 & 182 & 132 & 41 & 168 & 61 \\
\hline HDPE50/PLA50-Lot5 & 20 & 104 & 192 & 132 & 36 & 168 & 61 \\
\hline
\end{tabular}

\subsection{Thermogravimetric Analysis (TGA)}

In order to evaluate the thermal stability of the polymers, an analysis was performed to measure the degradation onset temperature $\left(\mathrm{T}_{\text {onset }}\right.$ ) (Table 6). PLA revealed a lower thermal stability compared to HDPE. In fact, $\mathrm{T}_{\text {onset }}$ was around $319{ }^{\circ} \mathrm{C}$ for PLA and $458^{\circ} \mathrm{C}$ for HDPE, which is in agreement with literature results [31]. Blending HDPE and PLA (HDPE50/PLA50) resulted in a $\mathrm{T}_{\text {onset }}$ near to that of neat PLA, confirming a reduced thermal stability of the blend $\left(322{ }^{\circ} \mathrm{C}\right)$ with respect to neat HDPE $\left(458^{\circ} \mathrm{C}\right)$. All formulations displayed a complete degradation of polymers without the formation of a residual char ( $100 \%$ of mass variation, $\Delta \mathrm{m}$, between the mass of the sample before the test and the residual mass after the test). The addition of Lotader AX8840 increased blend thermal stability, with higher $\mathrm{T}_{\text {onset }}$ when increasing Lotader AX8840 amount. The blend formulations, either 
compatibilized or not, displayed two separate thermal degradations, the first referring to poly(lactic) acid, and the second to polyethylene. A maximum rate of weight loss corresponded to each degradation. The blend formulations exhibited two separate temperatures of the peak value for the first derivative of the TGA curve ( $\left.\mathrm{T}_{\mathrm{DTG}}\right)$.

Table 6. TGA results for HDPE/PLA blends with different compatibilizer percentages and HDPE50/PLA50 matrix composites with $3 \mathrm{wt} . \%$ of compatibilizer. $\mathrm{T}_{\text {onset }}\left({ }^{\circ} \mathrm{C}\right)$ was evaluated with the extrapolated onset temperature from the TGA curve. $\mathrm{T}_{\mathrm{DTG}}\left({ }^{\circ} \mathrm{C}\right)$, temperature of maximum differential thermogravimetric analysis (DTG) curve peaks; $\Delta \mathrm{m}(\%)$ is the mass variation percentage between sample's total mass before the test and the residual mass after the test.

\begin{tabular}{cccc}
\hline & $\mathbf{T}_{\text {onset }}\left({ }^{\circ} \mathbf{C}\right)$ & $\mathbf{T}_{\text {DTG }}\left({ }^{\circ} \mathbf{C}\right)$ & $\Delta \mathbf{m} \mathbf{( \% )}$ \\
\hline HDPE & 458 & 474 & 100 \\
PLA & 319 & 351 & 100 \\
Poly & 459 & 480 & 100 \\
Lot & 434 & 464 & 100 \\
HDPE50/PLA50 & 322 & $345 / 471$ & 100 \\
HDPE50/PLA50-Poly1 & 316 & $351 / 444$ & 100 \\
HDPE50/PLA50-Poly3 & 322 & $358 / 438$ & 100 \\
HDPE50/PLA50-Poly5 & 313 & $342 / 432$ & 100 \\
HDPE50/PLA50-Lot1 & 325 & $350 / 470$ & 100 \\
HDPE50/PLA50-Lot3 & 325 & $350 / 468$ & 100 \\
HDPE50/PLA50-Lot5 & 334 & $351 / 474$ & 100 \\
\hline
\end{tabular}

\subsection{Attenuated Total Reflection-Fourier Transform Infrared Spectroscopy (ATR-FTIR)}

Infrared spectroscopy (Thermo Fisher Scientific, Waltham, MA, USA) was used to evaluate the interactions between polymers, whose main results are displayed in Figure 5. As expected, HDPE50PLA50 did not display peak variations, confirming the presence of an immiscible blend without interactions between HDPE and PLA. The addition of Lotader AX8840 slightly shifted the typical ester peak of PLA (1749 to $1752 \mathrm{~cm}-1$ ), suggesting interactions between glycidyl methacrylate and the $\mathrm{C}=\mathrm{O}$ group of PLA. Polybond 3029 addition, on the contrary, did not display variation of HDPE50/PLA50 peaks, confirming the hypothesis of poor interactions between maleic anhydride and the $\mathrm{C}=\mathrm{O}$ group of PLA.

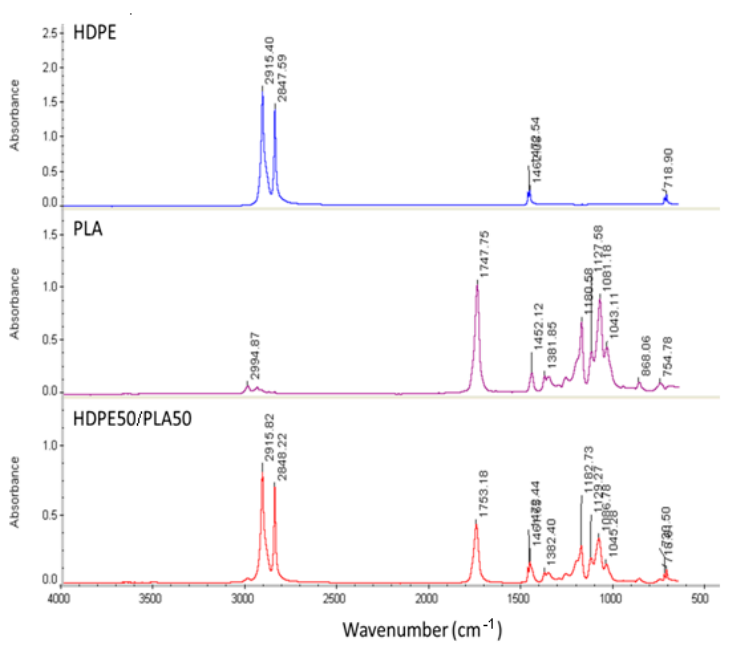

(a)

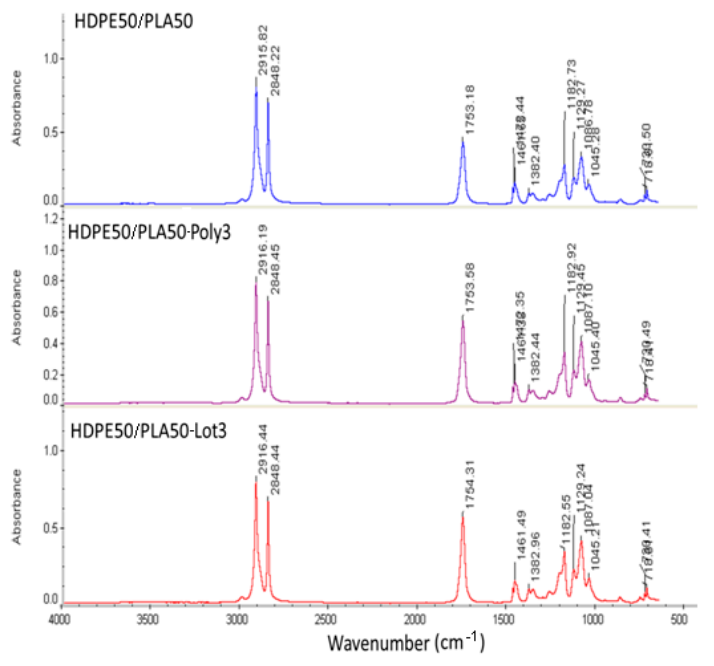

(b)

Figure 5. Attenuated total reflection (ATR)-FTIR spectra of: (a) HDPE, PLA, and HDPE50/PLA50, (b) HDPE50/PLA50, HDPE50/PLA50-Lot3, and HDPE50/PLA50-Poly3. 
Further research on compatibilization could involve the use of nanostructures, such as $\mathrm{SiO}_{2}$ nanoparticles, graphene platelets, or carbon nanotubes [32].

\section{Conclusions}

After a preliminary study on HDPE/PLA blends, the blend containing equal amounts of HDPE and PLA appeared to be the most suitable towards keeping good mechanical properties and a significant reduction of non-bio-derived charge. The addition of a compatibilizer, especially Lotader AX8840, with its high content of glycidyl methacrylate, seemed to increase the homogeneity of the blend. An appropriate percentage of a compatibilizer has to be selected in order to optimize a blend's properties. In fact, $3 \mathrm{wt} . \%$ of a compatibilizer seemed to optimize the mechanical properties (strength and plasticity) and the affinity between HDPE and PLA. SEM images revealed a typical immiscible morphology for HDPE and PLA when blended without a compatibilizer. Both Lotader AX8840 and, more moderately, Polybond 3029 seemed to increase the homogeneity of the blend thanks to the interaction of functional groups with PLA, which is in agreement with the FTIR results. Further analyses have to be done in order to evaluate the biodegradation behavior of oil-based-bio-derived polymer blends at the ratios analyzed in this study.

Author Contributions: Experiments were designed by M.V., V.M. and A.Q. A.Q. carried out the experiments, which were then analyzed also by M.V. and V.M. C.S. contributed to the discussion of the results and to the submission of the final manuscript. A.Q. wrote the paper, which was successively proofread by all the co-authors.

Funding: This research was funded by doctoral school of Sapienza Università di Roma, doctoral school of Institut National des Sciences Appliquées de Lyon and Vinci program of Université franco-italienne for PhD students in joined supervision between Italy and France.

Conflicts of Interest: The authors declare no conflict of interest.

\section{References}

1. Polypetchara, N.; Suppakul, P.; Atong, D.; Pechyen, C. Blend of polypropylene/poly(lactic acid) for medical packaging application: Physicochemical, thermal, mechanical, and barrier properties. Energy Proced. 2014, 56, 201-210. [CrossRef]

2. Parameswaranpillai, J.; Thomas, S.; Grohens, Y. (Eds.) Polymer blends: State of the art, new challenges and opportunities. In Characterization of Polymer Blend, 1st ed.; Wiley-VCH: Weinheim, Germany, 2015; pp. 1-6.

3. Higgins, J.A.; Lipson, J.E.G.; White, R.P. A simple approach to polymer mixture miscibility. Philos. Trans. R. Soc. A 2010, 368, 1009-1025. [CrossRef] [PubMed]

4. Utracki, L.A. Compatibilization of Polymer Blends. Can. J. Chem. Eng. 2008, 80, 1008-1016. [CrossRef]

5. Cook, S. Polymeric Compatibilizers: Uses and Benefits in Polymer Blends; John Wiley \& Sons: Akron, OH, USA, 1997; ISSN 00359475.

6. Kim, Y.F.; Choi, C.N.; Kim, Y.D.; Lee, K.Y.; Lee, M.S. Compatibilization of immiscible poly(L-lactide) and low density polyethylene blends. Fiber Polym. 2004, 5, 270-274. [CrossRef]

7. Quitadamo, A.; Massardier, V.; Valente, M. Oil-based/Bio-Derived Thermoplastic Polymer Blends and Composites. In Introduction to Renewable Biomaterials: First Principles and Concepts; Lucia, L., Ayoub, A., Eds.; Wiley: Hoboken, NJ, USA, 2017; pp. 239-268.

8. Ebnesajjad, S. Handbook of Biopolymers and Biodegradable Plastics, 1st ed.; William Andrew, Elsevier: Oxford, UK, 2013; ISBN 978-4557-2834-3.

9. Zhu, Y.; Romain, C.; Williams, C.K. Sustainable polymers from renewable resources. Nature 2016, 540, 354-362. [CrossRef] [PubMed]

10. Ermolovich, O.A.; Makarevich, A.V. Effect of Compatibilizer Additives on the Technological and Performance Characteristics of Biodegradable materials based on starch-filled polyethylene. Russ. J. Appl. Chem. 2006, 79, 1526-1531. [CrossRef]

11. Quitadamo, A.; Massardier, V.; Valente, M. Interactions between PLA, PE and wood flour: Effects of compatibilizing agents and ionic liquid. Holzforschung 2017, 72, 691-700. [CrossRef]

12. Luyt, A.S. Polyolefin Blends. In Polyolefin Compounds and Materials, 1st ed.; AlMa'adeed, M., Krupa, I., Eds.; Springer: Cham, Switzerland, 2016; ISBN 978-3-319-25980-2. 
13. Baiardo, M.; Frisoni, G.; Scandola, M.; Rimelen, M.; Lips, D.; Ruffieux, K.; Wintermantel, E. Thermal and Mechanical Properties of Plasticized Poly(L-lactic acid). J. Appl. Polym. Sci. 2003, 90, 1731-1738. [CrossRef]

14. Mekonnen, T.; Mussone, P.; Khalil, H.; Bressler, D. Progress in bio-based plastics and plasticizing modifications. J. Mater. Chem. A 2013, 1, 13379-13398. [CrossRef]

15. Javadi, E.; Babaei, A.; Nouri, M. Correlation of the morphological and mechanical properties of a biodegradable blend based on polylactic acid. J. Macromol. Sci. B 2017, 56, 194-201. [CrossRef]

16. Hamad, K.; Kaseem, M.; Ayyoob, M.; Joo, J.; Deri, F. Polylactic acid blends: The future of green, light and tough. Prog. Polym. Sci. 2018, 85, 83-127. [CrossRef]

17. Quiroz-Castillo, J.M.; Rodriguez-Felix, D.E.; Grijalva-Monteverde, H.; Lizarraga-Laborin, L.L.; Castillo-Ortega, M.M.; Castillo-Castro, T.; Rodriguez-Felix, F.; Herrera-Franco, P.J. Preparation and characterization of films extruded of polyethylene/Chitosan modified with poly(lactic acid). Materials 2015, 8, 137-148. [CrossRef] [PubMed]

18. Madhu, G.; Bhunia, H.; Bajpai, P.K.; Nando, G.B. Physico-mechanical properties and biodegradation of oxo-degradable HDPE/PLA blends. Polym. Sci. A 2016, 58, 57-75. [CrossRef]

19. Sailaja, R.P.N.; Chanda, M. Use of Maleic Anhydride Grafted Polyethylene as Compatibilizer for HDPE Tapioca Starch Blends: Effects on Mechanical Properties. J. Appl. Polym. Sci. 2001, 80, 863-872. [CrossRef]

20. Quiroz-Castillo, J.M.; Rodrigues-Felix, D.E.; Grijalva, H.; Castillo-Castro, T.; Plascencia-Jatomea, M.; Rodriguez-Felix, F.; Herrera-Franco, P. Preparation of extruded polyethylene/chitosan blends compatibilized with polyethylene-graft-maleic anhydride. J. Appl. Polym. Sci. 2014, 101, 1094-1100. [CrossRef] [PubMed]

21. Djellali, S.; Haddaoui, N.; Saoun, T.; Bergeret, A.; Grohens, Y. Structural, morphological and mechanical characteristics of polyethylene, poly(lactic acid) and poly(ethylene-co-glycidyl methacrylate) blends. Iran Polym. J. 2013, 22, 245-257. [CrossRef]

22. Zeng, J.B.; Li, K.A.; Du, A.K. Compatibilization strategies in poly(lactic acid)-based blends. RSC Adv. 2015, 5, 32546. [CrossRef]

23. Farah, S.; Anderson, D.G.; Langer, R. Physical and mechanical properties of PLA, and their functions in widespread applications-A comprehensive review. Adv. Drug Deliv. Rev. 2016, 107, 367-392. [CrossRef]

24. Ljungberg, N.; Wesslen, B. The effects of plasticizers on the dynamic mechanical and thermal properties of poly(lactic acid). J. Appl. Polym. Sci. 2002, 86, 1227-1234. [CrossRef]

25. Lu, X.; Tang, L.; Wang, L.; Zhao, J.; Li, D.; Wu, Z.; Ziao, P. Morphology and properties of bio-based poly(lactic acid)/High-density polyethylene blends and their glass fiber reinforced composites. Polym. Test. 2016, 54, 90-97. [CrossRef]

26. Madhu, G.; Bhunia, H.; Bajpai, P.K. Blends of high density polyethylene and poly(L-lactic acid): Mechanical and thermal properties. Polym. Eng. Sci. 2014, 59, 2155-2160. [CrossRef]

27. Gallego, R.; Lopez-Quintana, S.; Basurto, F.; Nunez, K.; Villarreal, N.; Merino, J.C. Synthesis of new compatibilizers to poly(lactic acid) blends. Polym. Eng. Sci. 2014, 54, 522-530. [CrossRef]

28. Thurber, C.M.; Xu, Y.; Myers, J.C.; Lodge, T.P.; Macosko, C.W. Accelerating reactive compatibilization of PE/PLA blends by an interfacially localized catalyst. ACS Macro Lett. 2015, 4, 30-33. [CrossRef]

29. Gregorova, A. Application of Differential Scanning Calorimetry to the Characterization of Biopolymers; World's Largest Science, Technology \& Medicine Open Access book publisher A Study of the Porosity of Activated Carbons Using the Scanning Electron Microscope; INTECH Open Access Publisher: Rijeka, Croatia; pp. 3-20.

30. Anstey, A.; Codou, A.; Misra, M.; Mohanty, A.K. Novel Compatibilized Nylon-Based Ternary Blends with Polypropylene and Poly(lactic acid): Fractionated Crystallization Phenomena and Mechanical Performance. ACS Omega 2018, 3, 2845-2854. [CrossRef]

31. Madhu, G.; Mandal, D.K.; Bhunia, H.; Bajpai, P.K. Thermal degradation kinetics and lifetime of high-density polyethylene/poly(L-lactic acid) blends. J. Thermoplast. Compos. 2017, 30, 773-793. [CrossRef]

32. Salzano de Luna, M.; Filippone, G. Effects of nanoparticles on the morphology of immiscible polymer blends-Challenges and opportunities. Eur. Polym. J. 2016, 16. [CrossRef]

(C) 2018 by the authors. Licensee MDPI, Basel, Switzerland. This article is an open access article distributed under the terms and conditions of the Creative Commons Attribution (CC BY) license (http:/ / creativecommons.org/licenses/by/4.0/). 